\title{
The (vertical) network firm as a political coalition: The reorganization of Fiat Auto
}

\author{
Josh Whitford \\ Department of Sociology \\ Columbia University \\ and \\ Francesco Zirpoli \\ Dipartimento di Ingegneria Meccanica \\ Università degli Studi di Salerno \\ Paper presented at the IMVP Automotive Research Conference
}

June 8-9, $2009 \cdot$ Oakland University $\bullet$ Rochester , MI

\section{DRAFT}

May 4, 2009

\begin{abstract}
The article argues that organizational sociology would do well to revisit James March's famed imagery of the business firm as a political coalition in light of today's decentralized production regimes. Specifically, we show that the increased tendency of firms to coordinate the design and making of highly complex products across organizational boundaries has fundamentally altered and been altered by the politics of coalition building. This is demonstrated using a 15 year longitudinal qualitative case study of the vertical production network that revolves about Fiat Auto. In those years, Fiat went from one of the most vertically integrated automakers in Europe, to one of the least vertically integrated, and has in the wake of a severe crisis now swung back the other way. We argue that this evolution cannot adequately be understood without reference to an interplay of inter- and intra-firm relations, including especially to the spilling of intraorganizational rivalries across firm boundaries, and to the effects of cross-firm coalitions on intra-organizational fights. Analyzing this evolution and these relations from a "political" perspective allows us to better understand the behavior not merely of particular firms, but also of interacting networks of firms in a world of blurred - but existent - organizational boundaries.
\end{abstract}




\section{INTRODUCTION}

The last quarter century has brought radical changes in the organization of production. Organizational boundaries have become so blurred that it is no longer controversial to argue, as Walter Powell famously did in 1990, that networks that are "neither market nor hierarchy" represent "a distinctive form of coordinating economic activity" (Powell 1990: 301). A burgeoning literature has since clearly shown that "network" forms of organization governance foster innovation, learning, joint investments, and joint problem solving activities, and that they tend to appeal to actors in volatile activities "where both markets and environments change frequently and there is a premium on adaptability" (Carruthers and Uzzi 2000; DiMaggio 2001; Podolny and Page 1998; Smith-Doerr and Powell 2005: 380). Much has likewise been done to theorize the functioning of network organizational forms and to identify the countours of their distinctive "embedded" logic of exhange (e.g. Helper, et al. 2000; Jones, et al. 1997; Podolny and Page 1998).

However, despite many advances - far more than we can name here - there remains a curious split in studies of network governance in organizational fields. Scholarship on intraorganizational networks has been extremely attentive to relations between actors or groups of actors, while scholarship on inter-organizational relationships has tended to focus on formal ties (Smith-Doerr and Powell 2005). Although the blurring of organization would seem to give good theoretical reason to expect dynamic interactions between internal and the external, only a few studies of network governance have grappled seriously with the ways in which the internal organization of potential collaborators fundamentally affects their ability to build alliances with others and to reach across boundaries (Azoulay 2003; Helper, et al. 2000; Kristensen and Zeitlin 2004). And to our knowledge, in studies of network governance no attention at all has been paid to effects that run in the other direction, that is, to the of the implications of external relations for the internal organization of potential collaborators.

In this article, we use a case study of the vertical production network that revolves about Fiat Auto to show that this inattention is no mere oversight. It is a real problem. Drawing upon extensive qualitative interviews conducted over a ten year period at both Fiat Auto and its suppliers, we analyze the Italian automaker's adoption of a very radical outsourcing strategy in the mid-1990s, turn then to a reorganization in the late 1990s that failed to stem the company's descent into a deep crisis that bottomed out in 2001, and close with an analysis of the much feted restructuring and recovery that occurred in the wake of that crisis -- a recovery that has resulted in the once all but unthinkable prospect that an automaker that was all but bankrupt just a few short years ago has been put forth as Chrysler's white knight. Across this reorganization, fall, and rise we argue that the behavior of both Fiat and its suppliers, and thus the evolution of the network, are all but impossible to understand without considerable attention to: deep rivalries between Fiat's technical and purchasing divisions that conditioned relations with and developments at key suppliers; to an ensuing balkanization of the company into a series of weakly overlapping cross-firm coalitions that often included personnel from suppliers; and to bargaining over strategy conditioned in no small part by the existence of those rivalries and coalitions. 
As a theoretical lens to understand this interplay of relations within and between organizations, we revisit one of the foundational ideas of modern organizational theory: James March's (1962: 672) famous claim that a business firm ought to be seen as a sort of "political coalition," in which "the executive of the firm is a political broker." In this image, "The composition of the firm is not given; it is negotiated. The goals of the firm are not given; they are bargained."

But -- and this is a big but -- we also use our case to show that that March's imagery cannot simply and naively be imported into a world in which the politics of coalition building have been fundamentally altered by the increased tendency of firms to coordinate the design and making of highly complex products across organizational boundaries. So while we begin with March's 1962 imagery, we will not end there. The point of the article is not so much to pay homage to those ideas as it is to use them to build new theoretical tools that can reorient that powerful imagery away from the behavior of particular firms to explain instead patterns of behavior in interacting networks of firms in a world of blurred - but existent - firm boundaries.

\section{THEORY}

In our case narrative, we retain much of March's seminal imagery, including most notably a model of the firm in which participants to coalitions make demands that constrain the executive. When those demands align (i.e. there is consensus), strategy is unproblematic and there is no real need to investigate coalitional politics. When those demands do not align (at least in the first instance), strategy is contested and things get more interesting. ${ }^{1}$ In such situations, March argued (and we concur) that organizational theory should investigate coalitional politics by breaking with "conventional economic views" in "four critical ways." (1) It should focus primarily on the actual operating organizers of key coalitions, and incorporate the objectives of owners or stockholders only insofar as they constrain policymaking. (2) It should expect that "at any point in time, there are a number of possible coalitions that are viable." (3) It ought to reject any presumption that conflict problems can easily be solved by "simple payments and agreement on a superordinate goal" and thus leave space for "sequential rather than simultaneous mediation of demands." (4) It should identify "institutional constraints on the solution of the coalition problem," including especially the "institutionalization of commitments through the organizational structure" and the "reification of attachments through identification and indoctrination."

Where we break with March's initial treatment is in its reference to suppliers only as relatively peripheral and separate (if interacting) players. In that treatment, suppliers may perhaps place demands on the executive, but their internal structure and behavior are not themselves simultaneously made the object of analysis. This simplification made sense in the context in which he was writing. Interactions between organizations were relatively straightforward, so the theoretical debates in which he was intervening were focused first on the behavior of particular

\footnotetext{
${ }^{1}$ We might as well have rooted our argument in Pettigrew's (1977) "Strategy Formulation as a Political Process." For ease of exposition and to keep things short, we focus on March's better known work in this section, as our main point is that political approaches tend to emphasize particular firms, or disputes between parts of firms, and downplay the role of external actors. Had we brought in Pettigrew here, our argument would not materially have changed. (See e.g. Pettigrew 1977: 81 "Political behavior is defined as behavior by individuals or — in collective terms - subgroupings within an organization that makes a claim against the resource-sharing system of the organization" ).
} 
organizations, and only then on their interactions. However, there has since been a dramatic restructuring of many industries, including especially the automotive industry from which we draw our empirical material.

American and European assemblers have responded to ever shorter product cycles, to the breakdown of national markets, and to the example of an evidently more flexible Japanese model of production by outsourcing huge portions of production to supplier firms in a conscious effort to transform their organizations from hierarchies into vertical production networks. Assemblers that might in the early 1980s typically have purchased roughly a third or so of their "cost of goods sold" from other firms typically buy closer to three-quarters of the value of their products (Veloso 2000). And they do so even as the products they make are made up of so many overlapping and interdependent subsystems, so many of which are differently amenable to radical and incremental innovations, that they cannot possibly be made or designed without hugely complicated relationships between organizations.

The implications of this industrial transformation are many. But for our purposes, one change stands out. Radical outsourcing markedly complicates the politics of coalition building -- both for those seeking to build coalitions and for organizational scholars trying to understand those coalitions -- in two ways. It has increased the intensity, complexity and frequency of individualto-individual ties at multiple levels across organizational boundaries. And it has raised the likelihood that the ability of particular actors (or groups of actors) in one organization to achieve their goals will depend as much on the actions of particular actors (or groups of actors) in other organizations as it will upon those in their own.

These complications certainly do not undermine March's political imagery, nor do they condemn the work of others -- such as Andrew Pettigrew (1977) -- who followed in his footsteps with his seminal depiction of "Strategy Formulation as a Political Process." If anything, we shall argue, those complications make the imagery of the business firm as a political coalition -- and of strategy formulation as a political process -- more relevant than ever. But they do mean that there is new theoretical work to be done. ${ }^{2}$ In particular, if we are to use March's approach to genuinely understand the behavior of interacting networks of firms in a world of blurred -- but existent -firm boundaries, we must be able to do more than simply identify coalitions that cut across organizational boundaries. We must also take care to explain why actors (or groups of actors) with divided loyalties ultimately enroll in one coalition rather than in another, and we must do so with a conceptual apparatus that can run across organizational boundaries.

To do that, and thus to do at least some of that new theoretical work, in our case narrative we supplement March's seminal imagery article with some ideas of more recent sociological vintage. Specifically, we rely upon an understanding of the political that goes beyond the simple (and trivial) assumption that observed coalitions reflect actors' interests ${ }^{3}$ to emphasize also that those

\footnotetext{
${ }^{2}$ Baum and Ingram (2002) do extend March's Behavioral Theory of the Firm to today's more decentralized organizational regime in their "Interorganizational Learning and Network Organization: Toward a Behavioral Theory of the interfirm." But Baum and Ingram notably do not even cite March's 1962 paper.

${ }^{3}$ We recognize that the term "interest" is potentially fraught. We obviously mean actors' understandings of their interests -- given that we allow them to form and to change -- but shall spare the reader the extra words each time we write the term and will just write "interests." What we can say, based on our research, is what actors understood to
} 
interests -- and actors' understandings of them -- are fundamentally shaped by actors' managerial ideologies and by their relational legacies. ${ }^{4}$

Our use of managerial ideology follows Barley and Kunda (1992): we mean "a stream of discourse that promulgates, however unwittingly, a set of assumptions about the nature of the objects with which it deals," including especially assumptions about the likely outcomes of actions under conditions of uncertainty. For our purposes, the key point shall be that different, and coherent, ideologies permeated Fiat's production network and served as the basis for calls to faction. Unlike many who have used the term in the managerial literature, we are not in this article concerned with the issues of labor control that animate the work of Reinhard Bendix or, more recently of Barley and Kunda (1992) and of Gantmann (2005). The key factional fights that animate the players in our story reflect instead differences in their understandings of the implications that particular product architectures have for the coordination of activities within and between organizations. While this may seem on its face an innocuous question, the sizable academic literature on "modularity" has made clear that in the automotive industry it is an issue of immense consequence and one that has been understood quite differently by authors

B

oth across time and across firms [See esp. MacDuffie; Sabel and Zeitlin]. And, as our case shall make clear, it can be an issue of consequence internal to a particular production network, as well.

By relational legacies, we mean those pre-existing patterns of social and business ties that have been roundly shown in the literature on "embeddedness" to shape actors interests by giving them insights into the motives, trustworthiness, and capabilities of others [cite Uzzi 1999: 500, and others], and that can thus motivate calls to faction. We understand the concept dynamically, in the sense that what happens today is "pre-existing" for interactions that occur tomorrow. And we neither presume nor expect that all actors in a particular organizational unit will have the same relational legacies vis-à-vis actors in other organizational units. Because automotive development projects are so complex, when we speak of "assembler-supplier" relationships, we are in fact talking about "many-to-many" relationships that often involve multiple organizational units both at Fiat and at suppliers and multiple people in each of those units. For convenience in the narrative, we will often refer to the relationships between the suppliers and the "purchasing" or "engineering" divisions of Fiat in relatively general terms. When we do so, we are in effect making an empirical claim about the consistency of relational practice across those groups of actors; given their common structural position, it is not surprising that one would often find such consistency. But there are at times quite salient differences within divisions and other organizational subunits, and where relevant, we will note those differences. ${ }^{5}$

be in their interests. And we can say that their understandings of what was in their interests was affected by how they thought about the world, and what they thought others were likely to do.

${ }^{4}$ We do not mean to suggest that these ideas are somehow inconsistent with March's original formulation. To the contrary, they are quite consistent with that formulation. They were simply -- and understandably -- left out of an approach less concerned with the interplay of faction across organizational boundaries. We invoke them here simply to help us reconstruct the theory for application to today's decentralized production regime.

${ }^{5}$ We emphasize also that we understand all economic action as embedded in social ties [Krippner] and thus will not draw on the common bimodal distinction between ties that are "arms-length" and those that are "embedded," where the latter are defined as more trusting. For our story, the relevant point is that pre-existing ties are conduits of 


\section{METHOD}

Our empirical argument draws upon a longitudinal qualitative study of key transitions in the evolution of the production network that revolves about Fiat Auto. In the next section, we draw upon that material to show that these transitions are in fact well understood using a "political" approach. As a prelude to that discussion, it is useful first to explain what data we have and how it has been gathered.

We have been studying Fiat Auto and its suppliers since 1997. In part, this has been done through analyses of industry publications, archival data, and company documentation for background characteristics on the sector and an understanding of formal norms and procedures at both Fiat and suppliers, as well as through conversation with "privileged observers" of the industry including especially representative of the Italian unions. But our primary sources of data have been 36 semi-structured interviews conducted with personnel employed by Fiat Auto, and 63 interviews conducted at 45 different first and second tier suppliers. Interviews were conducted in three waves: between 1997 and 1998; 2000 and 2002; and between 2006 and 2008. ${ }^{6}$

At Fiat, interviewees have included the Chief Technology Officer (member of Fiat Auto steering committee), the Human Resource Senior Vice President (member of Fiat Auto steering committee), the Product Portfolio Management Vice President (the manager responsible for product portfolio management and member of Fiat Auto steering committee), the Engineering \& Design Vehicle Concept \& Integration Director (manager responsible for systems integration for chassis and vehicle), the CEO of the Centro Ricerche Fiat (CRF), four of the five vehicle line executives (i.e. the engineers responsible for the development of cars in the small (A-B), medium (C), and upper (D-E) as well as the commercial vehicle segments), the Engineering and Design Human Resources Manager, the Engineering and Design Controller and two directors in Fiat purchasing. At suppliers, which vary considerably in size and capabilities, the roles of those interviewed varies considerably. But we have sought out those responsible for the commercial relationship with customers from the pre-offer phase till the end of the project, and those in charge of the component or system development.

Potential interviewees were primarily selected according to their links to the product development process or to the management of relationships that cut across organizational boundaries. Interviewees were identified and contacted in a variety of ways, ranging from cold calls to snowballing. When interviewees were amenable (which they were in the vast majority of cases), interviews were taped and transcribed. Interviews were generally conducted in Italian. Quotes used in this paper are translated by the authors. In analyzing the data, we have sought primarily to triangulate interviewees responses and company documents, systematically

information and leverage that would otherwise not be available. That information may well be that a particular actor is not trustworthy in some regard.

${ }^{6}$ The authors were independently studying the implications first of the radical outsourcing strategy that Fiat Auto had undertaken in the early $1990 \mathrm{~s}$, and then of the deep crisis that shocked the company and its many dependent suppliers in the first years of this century. The genesis of this article came when, in 2006, our joint discussions of independent work led us to a common belief that much of what we were finding did not match particularly well with the theoretical predictions of the literatures we were reading. We then undertook a new round of data collection in which we were very specifically attentive to the sorts of "political" issues discussed in this paper. 
comparing formal documents to the information gathered in interviews, and the information gathered in particular interviews to that gathered in others discussing the same or similar topics. ${ }^{7}$

In reporting the results of our analyses, we use direct quotes where possible. However, given the potentially sensitive nature of some of the material discussed in these interviews, we must at times be careful to protect the identities of informants. Often in organizational research, this is done by giving pseudonyms to companies. We do not identify supplier companies by name, but because there are so few assemblers in the world, to do the same with Fiat would be futile. Hence, the primary way in which we are able to protect informants is simply through volume. We have enough interviews and enough points of view that we can mask identities when necessary.

\section{THE CASE}

For much of the last half century, Fiat was exactly the sort of company that March surely had in mind when he wrote of the business firm as a political coalition. The automaker was a massive vertically integrated Fordist producer. It was riven with internal factional infighting and occasionally beset by severe crises, but it was also a powerful and stable going concern. In the late 1960s, Fiat Auto itself employed some 125,000 people, and provided work either directly or indirectly to an additional 125,000 at a series of highly dependent subcontractors. These suppliers were at the time almost appendages of the automaker, insofar as they had little outside business and Fiat supplied not only designs, machines, primary and semi-finished materials, but often even provided credit and other financial resources (Michelsons 2001).

By the time we pick up the story, things had changed considerably. Fiat had been among the most vertically integrated automakers in the world as late as the mid 1980s. Yet just ten years later, the company was among the least vertically integrated automakers in the world. Seventy percent of value had been designed internally at the end of the eighties, and $50 \%$ was produced by Fiat or by subsidiaries. ${ }^{8}$ In the mid nineties, the numbers were reversed: $70 \%$ of the value of both production and design was devolved to suppliers (with this latter figure rising to $85 \%$ for some models). Fiat employed 134270 people in 1989, this number had dropped to 82553 by 1999, and would continue to fall to around 40,000 at time of writing. Rising employment at suppliers is harder to track, since suppliers work for multiple assemblers and industries, and are located across the globe. But there is very strong evidence that employment in the components industry grew considerably (Whitford and Enrietti 2005).

What happened? Quite simply, Fiat went further and went more quickly than did most their competitors in the rush to outsource that characterized the industry in the late 1980s. The company sought quite explicitly and dramatically to blur corporate boundaries and to create a

\footnotetext{
${ }^{7}$ Because we have been studying the network for many years, we are in many cases able to compare interviewees retrospective descriptions of events to interviews conducted at the time. In many cases to interview people on the same unit of analysis (e.g. the allocation of design capabilities) but also on the same specific project.

${ }^{8}$ Those relatively high numbers understate the degree to which Fiat the value chain was quasi-hierarchically governed for two reasons. First, Fiat generally sourced design only for relatively standard and valuable components that were not difficult to integrate with other systems; suppliers were only responsible for about 50 of the 3500 technical drawing tables used in the engineering of Fiat's products (Zirpoli and Becker 2008). Second, the remainder of Fiat's 1200 suppliers, and particularly those making parts to Fiat's specifications sold the vast majority of their output to Fiat and were thus essentially captive (Whitford and Enrietti 2005).
} 
vertical production network amid what the director of new product development at the time told us was a broad consensus that the company had to "reduce assets and, at the same time, to leverage external sources of innovation." And the company did in fact reduce assets and did leverage external sources of innovation. However, Fiat also fundamentally remade relations between company leadership, divisions, departments and suppliers in ways that uncorked a series of inter- and intra-organizational processes that had deep implications for the evolution of the production network but that were not entirely predictable - or, at least, that were not predicted by company leadership.

Importantly, the fact that these processes were not entirely predictable does not mean we can say nothing about them. In the remainder of this section -- the empirical heart of the article -- we describe three "Marchian moments" in the evolution of the production network that revolves about Fiat Auto in a narrative that aspires both to use and to build theory. Because the swath of time we describe is long, and because our story incorporate many players involved in complex bargaining, that narrative we ultimately present is somewhat stylized. With that said, we emphasize that our moemnts have not been picked solely because they highlight changes in a key characteristics of organizational functioning identified as political by March and because they show that might once have been relatively segregated within particular firms has become fundamentally inseparable from goings-on across firm boundaries. We have also sought to capture substantively significant events that also show how Fiat and its production network have co-evolved over the last fifteen years..

We start inside Fiat with the claim that the an initial and overarching strategic consensus enabled radical outsourcing to occur, but then show that this consensus was quickly splintered by intraorganizational rivalries between factions of different ideological stripe. These rivalries conditioned relations with suppliers, and ultimately undermined those suppliers' ability and willingness to make joint investments that the automaker's strategy ostensibly required. In our second moment, we argue that a renewed commitment to that strategy by the dominant faction in the wake of Fiat's alliance with GM led mid-level managers to build ad hoc and uncoordinated relationships with suppliers instead of coordinating their activities with Fiat's centralized technical division. This essentially divided the production network into a series of weakly overlapping cross-firm coalitions, which further undermined the company's outsourcing strategy. Finally, in our third moment, we take up the issue of regime change. We analyze changes that took place in the wake of a profound crisis that left Fiat on the edge of bankruptcy in 2002, and look especially at the establishment of a new ruling coalition that put forth an alternative strategy built around a combination of in-sourcing, reacquisition of competencies, and a renewed commitment to collaborative relations with key suppliers. We argue that the contours of that strategy were bargained very much in reaction to - but also constrained by - the consequences of the company's approach to outsourcing in our previous moments.

\section{The first Marchian moment: $A$ consensus splintered as intra-organizational rivalries go inter- organizational}

Our first moment begins (though it does not end) amid an overarching ideological consensus. This should not surprise. It is virtually unthinkable that a transformation as profound as the one that reshaped the production network that revolves about Fiat could have occurred without deep agreement that the decentralization of production was inevitable. And in fact, it was common in 
interviews to hear the impetus for change described in such terms. Interviewees often used passive voice and spoke of abstract global forces in statements like that of a high level Fiat manager who told us that in 1998 that in the early 1990s "the pressure on OEMs was to become global manufacturers, to improve the quality of their products, and, above all to reduce production costs." These "trends," he continued, "called for a new supply strategy."

There seems also to have been little dissent, at least initially, on the broad contours of Fiat's strategic response to those pressures: the automaker bet big on the possibilities of a "system integrator" strategy built around a "modular" product architecture. ${ }^{9}$ This strategy, which was very fashionable in the auto industry at the time, was premised on the idea that design rules can minimize interdependencies between systems, thus simultaneously enabling: (1) "rapid innovation at the level of modules, each proceeding independently and at its own pace"; and (2) "reduced costs, from standardization of interfaces that minimize coordination costs during product development"(MacDuffie 2008). Based on this bet, Fiat restructured -- and shrank -- its product development organization by cutting much of its capacity to do direct component design. A high-level Fiat manager explained the company's logic, saying that the company interpreted modularity to mean that Fiat "should have the competence of integrating systems as its core competence" and could "substantially detach itself from certain component and systems technologies and [could] focus primarily on 'architectural' know-how" while "delegating to suppliers the complete development of certain technologies, those that we did not consider as core."

To support this strategy, the company put forth a new approach to purchasing in the face of a widely recognized dilemma: Fiat's historic suppliers were very flexible and cost effective, which potentially gave the company a competitive advantage; but excessive reliance on those suppliers for research and design was risky because the competencies of those suppliers had been limited precisely by their historic reliance on Fiat [cite Enrietti]. ${ }^{10}$ In response, the company put forth what was referred to as a "hybrid" supply strategy. The strategy was "hybrid" in a double sense. First, Fiat sought to remake the base itself in part encouraging foreign suppliers enter the Italian market by directing them towards local suppliers ripe for acquisition and by pressuring these local suppliers to sell or ally with global partners (e.g. by using monopsony threats to withhold business), and in part by helping many remaining historic suppliers to develop more

\footnotetext{
${ }^{9}$ For an extended discussion of modularity in the automotive industry, and of modularity in general,and its implications see especially Baldwin and Clark (2000); on the implications of modularity on the organization of the new product development process see Sanchez and Mahoney (1996); on modularity's broader implications on the evolution of networks and industries see Sturgeon (2002); on the implications of modularity in the specific context of the automotive industry see MacDuffie (2008); on the link between modularity and outsourcing see Fixson, Ro, and Liker, (2005); on the link between product architecture and modular task decomposition see Takeishi, and Fujimoto (2001).

${ }^{10}$ Fiat's director of Global Sourcing described the Italian automotive components industry at the time as one "composed of two major segments: a small number of large companies, mainly owned by Fiat or heavily dependent on it as their principal customer, and a large number of small firms that were either reliant on Fiat or on major Fiat suppliers." He said it did not compare favorably to what was available on global markets, saying that although Fiat "had done more co-design than [their] competitors, foreign suppliers had had developed more advanced R\&D structures due to the demanding technology level required by their local customers" [by which he meant German automakers], and due to the fact that they tended to have a "vast portfolio of customers and could take advantage of many sources of knowledge." This analysis is consistent with the academic literature on Fiat and its supply network in those years.
} 
sophisticated design and development capabilities by providing them with subsidized training and helping them to expand operations into more markets (Enrietti 1995; Whitford and Enrietti 2005). Second, Fiat management hoped to garner the benefits of collaboration without some of its risks by adjusting (hybridizing) purchasing principles borrowed from Japanese producers. To do this, the company put in place careful selection processes and formally designated some suppliers as worthy of "partnerships" premised on risk sharing, co-design, early supplier involvement in price setting, target costing, and so on, but sought to mitigate possible "lock-in" effects caused by those principles by carefully maintaining multiple potential suppliers for each component and pitting them against each other in what has been referred to as "controlled competition" (Zirpoli and Caputo 2003).

This coupling of a focus on system integration and a "hybrid" approach to collaborative purchasing did deliver some successes. The company was able both to reduce its asset base and to release a few relatively well-received models in the late 1990s (albeit models that were largely restyling of existing vehicles). Fiat was also in fact able partially to remake the supply base: numerous foreign components and systems suppliers to buy or build plants in Italy amid a broader tendency in the period for global first-tier suppliers to amortize their investments in R\&D across multiple markets; and many historic Italian suppliers did grow both organizationally and technologically, and began increasingly to win supply contracts from automakers elsewhere in Europe thus strengthening the overall system.

These successes, however, proved illusory. And so did broad support both for Fiat's system integrator strategy and for the hybrid approach to purchasing. Each was eventually undone and remade by struggles that might in a previous era might have played themselves out inside the automaker but that began instead to spill increasingly across organizational boundaries. In particular, it seems that the possibility (and necessity) of forming alliances with newly powerful players in the company's changing supply network fundamentally altered the underlying dynamics of a classic tension endemic to the industrial corporation -- that between those who in American factory parlance might be called "gear-heads" focused on novel engineering solutions, and "bean-counters" more concerned with ensuring that those engineering solutions be had without breaking the bank. ${ }^{11}$

It had been expected that modularity would mitigate these tensions by aligning the interests of these two groups, as per a claim common in the management literature at the time. ${ }^{12}$ Gear-heads, centered largely though hardly exclusively in the technical divisions, would surely enjoy the increase in what MacDuffie (2008: 10) refers to as "option value, i.e. the ability to provide new functionality and customization through mix-and-match combinations of modules" developed by some of the world's most innovative producers of automotive components. And the beancounters, with a power base in the purchasing and financial divisions, would surely benefit from

\footnotetext{
${ }^{11}$ It would be tempting to speak of divisions, as these groups do map closely in many cases to divisions at Fiat. But they do not always so map, so to do so would potentially mislead. In the disputes we describe our interviewees speak of actors, ideas and power working in concert (or not) and thus are effectively referencing factions and coalitions, but did not use these or similar terms. We have thus chosen this nomenclature for particular rough aggregates of actors, and feel they evoke as accurately as anything we could come up with. But we do emphasize that they are our conceit, and not the responsibility of interviewees.

${ }^{12}$ See MacDuffie (2008) for an excellent overview of 15 years in the life and times of the concept of "modularity" in the automotive industry.
} 
"standards for modules that generate a larger number of potential suppliers and allow switching among suppliers more frequently on the basis of better price information and intensified competition" (MacDuffie 2008: 10).

Prior expectations notwithstanding, Fiat's embrace of modularity seems ultimately to have amplified the tension between the gear-heads and the bean-counters. It turns out that support for the system integrator strategy - while real -- had masked deeper ideological (in our sense) differences over just what a modular product architecture required and implied. The beancounters did see great savings to be had from the standardization of components, but they were also wary of hold-up risks that potentially arose given (1) that Fiat's outsourcing of design and ensuing reductions of technical personnel left the company poorly positioned to assess costperformance tradeoffs in complex components with multiple interactions; and (2) the company would now be relying heavily on a limited number of global system suppliers with which they did not have strong existing relationships. This fear manifested itself in an interpretation of the hybrid purchasing strategy perhaps best captured by an interviewee at a supplier who used some very evocative terminology. ${ }^{13}$

He said that Fiat's outsourcing and reconstruction of its external production network was not done using the traditional principle of "natural selection," by which he meant "leaving everyone to do their job until you lose faith in him and then you go find someone else." Instead, the purchasing division in particular was engaged in what he referred to as a form of "eugenics"14 that drew heavily on what we have called relational legacies in order to ensure the continued presence in the supply base of some relatively dependent companies that they could use to enforce price discipline in negotiations with the more sophisticated suppliers to which larger systems were assigned. The interviewee explained that the purchasing division was concerned that they did not generally have strong enough ties to global systems suppliers to ensure that these ensure that these firms did not "associate" with each other (i.e coordinating bids and hiding costs in the bowels of systems Fiat no longer understood so well given that they were no longer doing much direct component design). Hence, although Fiat would put technologically advanced systems and module suppliers into open competition for contracts, they would also demand that contract-winning system and module suppliers assign the production of particular components to a trusted cadre of often smaller and relatively dependent subsuppliers selected by the purchasing department. They could then use their strong relationships with, and extensive knowledge of, the many smaller companies in its historic Italian supply base, to ensure that at least costs on these subcomponents were kept low.

\footnotetext{
${ }^{13}$ We explain the issue using his description. But we emphasize that the basic contours "eugenic" approach he describes were described to us many times in different interviews.

${ }^{14}$ We are certainly aware of the historic connotations of this term, and know that on at least one occasion an otherwise sympathetic reader was dismayed that we would use it in this context. We apologize to anyone who is offended, but we do think it is the best term to make our point. Darwinian metaphors, or at least the invocation of "natural selection" are standard in discussions of supply chain management. In this case, process was decidedly not natural selection in the sense that the fittest firms survived, giving the supply network itself whichever traits emerged. Rather, the spot-assignment of contracts to sub-suppliers was intended deliberately to ensure that the supply network had particular traits deemed desirable, not least among these an ample contingent of trusted if undercapitalized suppliers that could be used to ensure short-run price discipline in the bidding process.
} 
This approach did in fact control costs, but it also frustrated efforts by a subordinate "gear-head" faction that was particularly concerned with strengthening relationships to larger systems and component suppliers. This faction was not exactly unconcerned with holdup problems. But they were mostly worried about what Chesbrough and Kusonoki have referred to as the "modularity trap." Put briefly, the standardization of interfaces and componentry can leave a company illpositioned to incorporate novel but more "integral" technologies into their new products. Fiat's proposed organizational solution to (or at least mitigation of) the modularity trap was ostensibly centered in a group in the technical division called the "Components Development Platform" (hereafter CDP) . The CDP, with around 120 in staff, was charged with the development of a set of underlying engineering concepts (a class of solutions to engineering problems) that the company hoped would be flexible enough to satisfy multiple scenarios. If the CDP had not developed or was not willing to develop a specific system in-house - as was the case more often than not given the company's broader downsizing of technical personnel - they would work with a panel of suppliers to develop the system in question. By standardizing concepts that were then to be handed off to the product development teams, the company hoped to speed up the development of components and to increase the likelihood that those components could themselves be standardized across models (from which cost savings would ensue).

Perhaps this organizational solution could have worked had coalitions formed differently. At Fiat, it was undermined by: (1) the dominance of a marketing department that successfully pushed for the rapid introduction of new functionalities on the assumption that modularity would ease system integration and that was thus inattentive to the relationship of those functionalities to the conceptual solutions put forth by the CDP; and by (2) the aforementioned "eugenic" approach to supplier selection regnant in Fiat's purchasing department. The problems were put bluntly to us by an engineer in the CDP who said that his division was often in the unenviable position of trying to enlist supplier support for projects without being able to guarantee business even for promising engineering solutions.. His division, he said, could "never be sure that the platforms will use our engineering solutions. Sometimes we go on for years and the engineering solutions we find never find space in vehicle developments" for reasons that were as much political as they were technical. "It is not a matter of what engineering solution better suits the new product" he continued, "it is a matter of who has the right to decide on that." And the fact is that, "the power equilibrium was still in favor of the purchasing department whose task was to lower the price of supply while improving the quality standards of the component purchased."

This inability of those in the gear-head faction to win the ideological battle in their own organization had dynamic implications. Put simply, an alliance between elements of the purchasing and marketing department with a core group of historic suppliers impeded the efforts of others in the company to get global systems suppliers to commit resources to the modular product architecture at the base of the company's broader approach to outsourcing. An interviewee at one of the world's leading component suppliers, for example, explained his own company's reaction to entreaties from Fiat's engineering and technical divisions for help designing systems and modules. He said that because they were "always oriented towards the customer" they had taken a few steps in that direction but had ultimately been frustrated by the fact that when it came time to assign production they had to deal with "these fellows in purchasing who want to outsource, but they don't want to do it component by component; they want to do it piece by piece. ... They say 'I'll buy it for you, you put it in, and you are 
responsible." This gave his company the worst of worlds: "if I have to take responsibility for the whole group, clearly I have to know the product, I have to invest, develop know-how, and this raises my costs" which only makes sense if there are efficiencies to be got elsewhere. However, the only place to get those efficiencies was from the direct management of sub-supply relations so that they are able to leverage sup-supplier expertise in co-design. This is precisely what was denied them by Fiat's "eugenic" approach to purchasing. Hence, because "their capacities did not really match this other type of logic" and, because they had "never entirely believed in" Fiat's rhetoric of modularity and full system supply, they endeavored (successfully) to hold onto Fiat as a client even as they were careful to supply only components and avoided getting enmeshed in the design and production of the larger modules that Fiat sought.

\section{The second Marchian moment: the formation of cross-firm coalitions}

Our second moment occurs as the cracks that became a crisis were just beginning to appear. Fiat's costs had come down through the 1990 s, but so had sales of the three main brands (Fiat, Alfa Romeo, Lancia). The company's share of the Italian market, $42.6 \%$ in 1997 , fell by $17 \%$ to $35.4 \%$ in 2000. In Western Europe more broadly, share declined from 11.7 to $9.5 \%$. This weakening of sales fanned fears that the company was simply too small to compete in an automotive industry that had gotten ever more oligopolistic through the 1990s, which in turn underpinned a new consensus among all parties that something had to be done (Camuffo and Volpato 2002). ${ }^{15}$

And something was done. In March 2000, Fiat and GM announced with great fanfare that they would create two 50/50 joint ventures (for South American and European markets; North American and Asian markets were excluded) - one for purchasing, and one for powertrain design and manufacturing, which represent between them some $80 \%$ of total vehicle manufacturing costs (Camuffo and Volpato 2002). Though backed also by an exchange of stock and of a "put" option, company statements made clear that the joint ventures were neither parts of a merger nor the prelude to a marketing agreement. To the contrary, the objective was simply to reduce costs without compromising quality, as encapsulated in the motto of the agreement: "allies in costs, competitors in the markets." And this, the story went, could be done by working with GM to develop commonalities in product architectures across select models. Fiat triumphantly reported that the alliance could generate such massive scale economies in purchasing that they would by 2005 be able to save as much as $\$ 2.5$ billion annually.

In practice, the alliance did not deliver as promised and the savings never materialized. In part, this was due to a further collapse in sales. But that was not the main problem. Volumes on particular components -- whence the savings and leverage were to come -- depend upon some standardization across models. And this did not happen. Not only did Fiat and GM fail to standardize components and systems across platforms to a degree sufficient to generate any real scale economies, Fiat proved unable to standardize componentry across even its own models! Indeed, we were told by Fiat's current Chief Technology Officer that upon his arrival in $2006-$

\footnotetext{
${ }^{15}$ This consensus, as Camuffo and Volpato (2002: 338) write, (prior to company's 2002 crisis) held that "the Fiat Group could have kept on going on its own, but it would have been a highly risky move. A negative trend in the domestic market or in Europe, or the unsuccessful launch of [an important] new model ... would have been enough for the top management to face a situation [that would have been] hard to manage."
} 
after the alliance had already been almost entirely dismantled - he had "reverse engineered many Fiat cars belonging to the same and different segments." What he found was shocking (for an engineer, anyway). He said that the models contained such a mish-mash of solutions to engineering problems that "nobody would have said, just by looking at the components and how they were engineered, that the two cars were produced by the same firm." Going forward, he said, Fiat could "make a lot of money just by bringing components commonality to a decent level."

What caused this striking failure of coordination? The story is in part the obvious one. Jointventures are famously difficult to pull off because they require considerable meshing of disparate corporate cultures [citations], so it ought not to surprise that many Fiat engineers were unhappy at suddenly being forced to work with GM engineers and answer to GM managers. Nor did it help things that the purchasing division's relations with many suppliers was worsened by a perception in the supply base that the alliance with GM had made the company more willing to use the threat of "global sourcing" to force cost reductions without accompanying technical discussions of the sort that might uncover alternative solutions.

But we caution that it would be highly misleading to ascribe Fiat's failure to standardize components across models only to disequilibria wrought by the sudden entry of a powerful new player into the production network. In fact, our interviews suggest that those failures were at least as much the contingent outcome of a broader political struggle that incorporated actors across a broad swath of the production network. Specifically, we find that the alliance with GM, while important, is best understood as just one part of a more extensive reorganization that seemingly consolidated the power of the dominant coalition described in our first moment by ensoncing their understanding of the implications of Fiat's modular outsourcing strategy in the structure of the company's product development organization, but that as it turns out gave also rise to a series of uncoordinated runaway product development coalitions between dissatisfied engineers at Fiat and their interlocutors at key suppliers. These cross-firm coalitions tended by their very nature to focus on local rather than global solutions to engineering problems, thus making it considerably more difficult to standardize components across models.

To understand how these coalitions emerged, it is useful to recall from our first moment that the dominant coalition at Fiat had long been wedded to idea that standard interfaces between modules would enable easier switching between suppliers and had therefore pushed the company to engage in what is referred to as "black-box" sourcing in order both to leverage supplier design resources and to free Fiat of the need to get actively involved until relatively late in the game. ${ }^{16}$ The reorganization with GM was used to move the company even further in this direction, as it led to a disbanding of the CDP -- the beleagured unit we described in our first moment that had been responsible for early conceptual development. Its mission, quite simply, was excised from Fiat's "core competence" by a dominant coalition convinced that suppliers could do it as well, so the CDP's personnel were folded into the increasingly centralized but still relatively small technical division (Product and Process Engineering) and suppliers were given almost total control of the development of major components and systems, from conceptual development

\footnotetext{
${ }^{16} \mathrm{NB}$ : this understanding of modularity and its implications had broad support in the managerial literature. For an overview of the interpretation of modularity in the auto-industry see MacDuffie $\{2008 \# 1274\}$.
} 
through application into vehicles (though still subject, as noted above, to "eugenic" interventions by the purchasing department).

This organizational structure freed Fiat from heavy involvement in product development until it was time to integrate systems in the development phase, but the company did anticipate the need at that stage to be able to "mix and match" technologies by switching suppliers in response to the demands of the market. Hence, although system integration tasks remained as had long been the case in what were referred to as "product development platforms," these organizational units were stripped of their permanent engineering staff and made explicitly into project teams -- a move both to make them more flexible and to acknowledge that de facto they were often staffed primarily by engineers who drew their paychecks from supplier firms. Meantime, to safeguard against the risk that a reliance on relatively off-the-shelf technology would eliminate the distinctiveness of its brands, Fiat then further fragmented the organizational structure by creating distinct business units for each brand and placing the platform teams under these business units.

This left one major organizational problem: how to ensure that new models came out on time and on budget. Fiat's solution was to put the platform teams under the control of executives modeled after the "heavyweight" product managers of Toyota fame and, at least in theory, to give them a great deal of power. They did have to work within the constraints of the company's broader product architecture -- established in the pre-development phase -- and with suppliers that had been blessed by the purchasing division, but they were to be supported by "competence centers" in the centralized technical division and, most importantly, had considerable "decision rights" regarding performance tradeoffs when interactions between systems did arise.

However, as has since become clear, the simple right to make decisions matters little without access to the information and know-how needed to make those decisions. System integration had been pushed into the development phase under the assumption that the relative standardization of interfaces between those systems would substantially eliminate reduce the need for extensive fine-tuning and adjustments at that late stage. In part for reasons outlined in our first moment (i.e. the neutering of the CDP and the relative unwillingness of key suppliers to invest substantial resources in the development of those interfaces), and in part due to the inherent difficulty of standardizing interfaces between systems in something as complex as a car, ${ }^{17}$ it turned out that this assumption had been overly optimistic. Fiat's platform teams, we were told, quickly found themselves overwhelmed (Zirpoli and Becker 2008).

As one platform team manager later told us, he had felt in those years like he had been expected to "be a 'magician.' Everything was under the control of the manager responsible for the vehicle. It was just impossible to cope with all aspects of product development, from technical to economic issues." It had been an almost impossible situation. As we were told (again retrospectively) the stakes had been very high because vehicle-level performance was tested so late that "maneuvering space for improving and fine-tuning performances was obviously very limited" and changes "were extremely costly and incurred the risk of quality problems." But at

\footnotetext{
${ }^{17}$ While we recognize that developments in the industry and academic literature in years since our second moment give reason to doubt that adequate interfaces between systems even could have been designed, for us the important point is that it had been expected at least by the dominant coalition, if not by many suppliers who, as we noted above, had in many cases never been entirely convinced.
} 
the same time, he also said, the tools and talent that platform teams had at their disposal was increasingly limited because the devolution of so much of the pre-development phase to suppliers had taken its toll on the ability of Fiat's centralized technical direction "to set performance targets to suppliers and to monitor [suppliers] work" as well as "the ability to manage performance tradeoffs."

The result, while perhaps not predicted, now seems predictable. As we were later told by a highlevel Fiat engineer, in those years "each platform had tended to develop their 'own' cars with very few concerns about component and platform sharing," an effect worsened by the division into business units which had "reinforced the attitude to not leverage systematic sharing of components and systems." The issue, it seems, is that product development platform teams responded to the need to be magicans by "going native." They formed alliances with the suppliers that -- in many cases -- formed a majority of their technical staff and treated Fiat's ostensibly centralized "engineering division was just another engineering supplier happened by chance to be part of the same firm."

Suppliers, who had become increasingly wary of the centralized purchasing division in the wake of the alliance with GM, thus had very different relationships with platform teams. With business assigned, and with control of the pre-development phase, they enjoyed a certain protection of future business on those models and thus tended to cooperate in the resolution of pressing engineering problems. However, although they did have an interest in helping Fiat to standardize components so they could spread their own costs across models, they did not have good means to do so since their strong ties to the automaker were not with a decentralized federation of business units tied together through a matrix organization but were rather with a balkanized collection of platform teams that did not even themselves have strong connections to the center.

\section{The third Marchian moment: regime change}

Our third moment is about regime change in the production network that revolves about Fiat Auto. The catalyst for change was a severe crisis that, while years in the making, came to a head in the fall of 2002 as it became clear that the alliance with GM had already essentially failed. The automaker was awash in debt, and had a net operating income that had been mostly negative since the late 1990s and that had fallen precipitously in 2002. There was much speculation in the business press that Fiat was not long for this world. In 2003, for example, the magazine The Economist was disdainful of Fiat's "drastic job cuts and plans to raise euro 1.8 billion through a share issue," writing that "even Italians" were spurning Fiat's cars and that "the firm's third rescue plan in two years [was] unlikely to be enough" to "avoid going bust."

Obviously, Fiat did not go bust. To the contrary. By 2008, the Economist was so impressed with the Italian automaker that the magazine was writing instead of a "remarkable industrial and financial turnaround that is likely to be pored over in business schools for years." 18 And as we write, Fiat is being bandied about as a possible savior to Chrysler -- an outcome that would have seemed unthinkable a few short years ago.

\footnotetext{
${ }^{18}$ See The Economist (June 26, 2003), "Can it be Saved"; and The Economist (April 24, 2008), "Rebirth of a Carmaker."
} 
A full accounting of the causes of the crisis and of the reasons the company's response was so successful is well beyond the scope of this article, let alone this moment. With that said, our analysis and data do shed light on the ways in which politics and relations internal and external to the automaker have shaped, constrained and enabled that response. Many journalistic accounts of the turnaround emphasize the arrival of a new executive. From our perspective, while the arrival of a new executive matters, that arrival ough in many cases to be seen to be as much consequence as cause of a broader shift -- as is in fact what happened at Fiat. In particular, our interviews suggest that the crisis created a political window of opportunity for a new leading coalition dominated by a resurgent engineering division, supported by key systems suppliers, and abetted by new leadership at a purchasing division put into flux by the full collapse of Fiat's joint-ventures with GM in 2005. Led by this coalition, and with proponents of the company's modular outsourcing strategy discredited by perceived relationship of that strategy to the crisis, the company started committing substantial new resources to information-sharing and complex collaboration across firm boundaries even as it sought or was forced to in-source some design tasks and to reacquire or otherwise underwrite some troubled suppliers.

The degree to which the particular approach outsourcing and modularity taken at Fiat has come to be seen as a mistake rang clear in numerous interviews conducted after the crisis not only at the automaker, but also at suppliers. The consensus view was that Fiat had wrongly presumed that the definition of interfaces between systems would put suppliers in a position to coordinate the production of those systems absent an explicit coordinating role for the automaker, and that this presumption had led the automaker to allow its own internal component design capabilities to so erode that it had become unable to perform this coordinating role.

A supplier we interviewed, for example, explained that they had been responsible for the performance of the occupant safety system "even though [they] did not control the design of all the subsystems involved," nor were they "responsible (or even competent) for the design of the chassis, the engine layout and packaging of components and systems that affect the performance of the occupant safety system." Yet when they met with Fiat engineers to "consolidate lessons learnt and draw some best practices to extend for future projects" after a "successful frontal crash test of a key vehicle," they discovered that nobody understood why the system had worked. As a result, he said, Fiat recognized that "they could not leave to serendipity the fate of the next occupant safety system" and re-internalized overall responsibility for the system, leaving the supplier responsible only for the development of parts and components (which was notably the supplier's preference as well; the additional responsibilities had not been profitable).

Interviews at Fiat made clear not only that such experiences were common, but that they also created a problem the company could not easily resolve. As we were told in 2006 by a high-level manager in Fiat's technical division, the company had outsourced so much design that it had essentially lost its ability to design many relevant systems, which in turn caused many projects to spiral out of control in terms of cost, quality and lead time. In retrospect, he said, it had been "naïve to believe that we could integrate a system without holding an in-depth and detailed knowledge of the components that are going to affect the performance of the entire car." Referring to the company's technical division, he said that they "realized that you cannot integrate components you know very little about" and had learned that "it is very difficult to understand the subtle interactions with the rest of the vehicle" when "you have never designed a 
component or a system." However, he also said that while this meant that company should ideally "have reversed [its] strategy by integrating back competences that [they] had lost," they had "two problems: no money and no time."

Despite these resource constraints, the technical division did have one very valuable asset: a window of political opportunity. The gravity of the crisis and fact that the company was losing money even on projects where sales were quite good ${ }^{19}$ had not only discredited an approach to outsourcing premised on modularity, they had given the company's new Chief Technical Officer a mandate to restructure relations internal to the company. And the unwinding of a purchasing alliance with GM that had been characterized by quite harsh bargaining tactics under the guise of "global sourcing," coupled with the enhanced profile of their preferred interlocutors in the engineering division, increased the willingness of key suppliers to work closely with the company and to commit resources to a recovery strategy premised on the release of several new models in the space of just a few years.

The central engineering function, which had hitherto been engaged primarily in project management and delegation to suppliers, was reorganized to resolve two perceived problems. First, a specific organizational unit was established and directed towards the integration of systems much earlier in the product development cycle. This eased the lives of the ostensibly "heavyweight" platform managers that been so beleagured in our second moment. Returning these project oriented units to the Fiat fold encouraged them to interact to a greater degree with centralized functional areas engaged in system and component developmen. Second and relatedly, Fiat reorganized the product development process in the hopes of re-acquiring some the knowledge of component design that gone lost in previous years. ${ }^{20}$ However, for the reasons cited above, this reorganization had to occur quickly and without significant increase in headcount. This was done by distinguishing between two project typologies and, accordingly, between two different relationships with first tier suppliers. For template projects, Fiat took responsibility for the integration of the components and systems within the vehicle. In order to do this, the company has had to to some hiring of personnel with the requisite skills, but for the most part the point has been to work actively and collaboratively with first-tier suppliers in the development of some models in order first to learn through direct exposure (learning-by-doing) what is happening at the cutting edge of component design, and second to use this knowledge to develop an understanding of interdependencies between systems. The company then sought to compensate for its resource constraints by exploiting this understanding for derivative projects in which suppliers are given more design and engineering specifications but are then left to do much of the development work themselves. ${ }^{21}$

\footnotetext{
${ }^{19}$ By "good" we mean sales similar to those competitor products generally perceived to have been well-received. Fiat's problems controlling costs were largely due to problems on the design side (note that we are here including as costs attributable to design issues those manufacturing costs that are a consequence of engineering mistakes or difficult manufacturability, and for subsequent quality problem and warranty costs).

${ }^{20}$ See Zirpoli and Becker (2008)for a detailed discussion of this reorganization.

${ }^{21}$ Note that the same supplier can and often does work on template and derivative projects. Suppliers have said in interviews that they are well aware of the relational implications of being involved in projects that have different purposes. See Herrigel and Wittke (2004)for a discussion of suppliers willingness - and even desire - to maintain a portfolio of relationships to their customers. Leveraging the shorter time to market and lower costs of derivative projects, this strategy is also helping Fiat to maintain the promised pace of new models introduction (the plan is to introduce 17 new models based on 6 templates for an overall number of 23 new models by 2010).
} 
Fiat thus remains as dependent - if not more dependent - on suppliers as it was in years previous when a higher percentage of design was conducted at those suppliers, but the mode of interlocution had to change. Suppliers had to be convinced that Fiat had no intention of marginalizing suppliers' contributions to design, but that the company was in fact genuinely aiming to learn enough to better collaborate in those activities. ${ }^{22}$ As a major component manufacturer reported to us, in years just previous "relational differences [had been] determined by our bargaining power, not by our competences." This was hardly a foregone conclusion, but does seem to have occurred, at least to some degree - not least because the purchasing division, released from the alliance with GM, placed under the control of a manager who made his career on the engineering side of the company, has been relatively supportive of changing needs the technical division.

This was made clear to us in interviews conducted in 2008 with managers in the purchasing division (and verified by suppliers; more on that below). They said that while the joint-venture with GM had not been an entirely negative experience, and that they had learned some lessons, on the whole they had no intention of retaining what they held to be an overly "rigid" and adversarial approach that often included online reverse auctions. Such an approach, they said, can deliver cost savings, but over the medium and long term it had created a series of problems that "made it difficult to manage the supply base" and had led them to reject what we referred to above as the "eugenic" approach. The constant pressure to cut costs had left some of the company's historic and more dependent suppliers (including some referenced in our discussion of eugenics above) on the verge of bankruptcy; and at the same time, those same pressures had left more technologically advanced suppliers wary of investing in projects with Fiat because they "had no certainty about the future and would have deals they had struck repeatedly renegotiated."

The former problem has forced "tactical" changes in purchasing strategy as the company has in recent years to "save" a series of its historic suppliers lest their failure shut down Fiat production. This has been done in some cases through emergency credit or by locating and assisting buyers, in others Fiat has acquired the troubled companies in what amounts to an accidental (and expensive) in-sourcing of activities previously outsourced. The response to the latter problem has been more strategic and at least on its face is supportive of the engineering function's need for closer and more consistent collaboration with suppliers throughout the entire design phase. In our interviews in 2008, managers at the purchasing division spoke openly about the "absurdity that we had suppliers that were supposed to do co-design but we didn't know what to ask for and what to verify" and made much of the fact that to help remedy this they had begun assigning multi-year contracts - a practice they had entirely renounced during the alliance with GM "even on new models" and that they were "committed to maintaining those contracts for several years." 23

\footnotetext{
${ }^{22}$ Note that the involvement of suppliers on template projects resembles the approach Fiat attempted with the Component Development Platform in the mid nineties. Suppliers are involved in real projects with units that do generally have the wherewithal to ensure the later assignment of parts production. The CDP was involved only in pre-industrialization efforts and, as it turned out, had trouble guaranteeing that supplier efforts would turn into production volumes.

${ }^{23}$ As is standard in the industry, these contracts presupposed annual cost reductions of around 3\%. But here again, the ostensible practice was collaborative in that these percentages were bargained and consideration was made of constraints imposed e.g. by commodity prices or other factors specific to market considerations.
} 
There has, in short, been a fairly broad-based renunciation of a managerial ideology that downplayed interdependencies and held that innovation was better bought than made, in favor of another that at least in the abstract risks leaving the automaker again at the mercy of a supply base in some cases overly concentrated on the Italian market, and in others large and global enough to find Fiat's relatively low volumes unworthy of significant attentions. With that said, recent years have certainly shown some real successes with the release of some very wellreceived models that have made money for both Fiat and many of its suppliers. Indeed, suppliers we interviewed told us that they were happy enough to "lose" some system integration tasks and to concentrate on component development where profit margins tend to be higher. They also said that while it had become harder to exploit gaps in Fiat's know-how in the offer phase, they also felt that this was counterbalanced by the reduced risk of project failures and by opportunities in terms of learning and enhanced joint problem solving that the new relationship with Fiat could entail.

Suppliers we interviewed thus said, for the most part, that they were supportive of Fiat's new approach. But they also made clear that the jury was still out, as there have also been enough countervailing experiences that they remain cautious. We were told, for example by a particularly important systems supplier that the day after signing a major agreement with the director of the purchasing to standardize a costly component over seven different models with huge cost savings for both companies, he received a letter announcing a non-negotiable demand for an across the board price cut on parts he was currently supplying. And while he said that the experience had not changed his view that the agreement just signed would on balance be favorable for his company, it does underscore that the production network that revolves about Fiat Auto remains a muddled coalition of sometimes opposing and mutually inconsistent factions that will by no means remain united in the face of what is by all accounts the tremendous challenges facing the industry going forward.

\section{DISCUSSION AND CONCLUSION}

As we hope has been made clear in our whirlwind tour of fifteen years in the vertical production network that revolves about Fiat Auto, the evolution of that network has broadly mirrored trends in the industry as a whole. Fiat, like other automakers had been relatively vertically integrated until the 1980s. And like automakers elsewhere, the company responded to the breakdown of mass markets and the advent of more flexible technologies by selling off component divisions and radically outsourcing first production and then design. Fiat's commitment in the 1990s to a developing a modular product architecture under the presumption that this would ease coordination across firm boundaries was also consistent with trends that cut globally across the industry, and Fiat was hardly alone either in its attachment to, or in its subsequent rejection of, that commitment. But as we hope has also come clear in our whirlwind tour, Fiat has also taken these trends to some relative extremes. The company that was Europe's most vertically integrated major automaker in the late 1980s was not only the continent's most decentralized automaker just ten years later, it was also among the most committed to the dream that the car might someday be become like the personal computer - modular enough to be made and designed almost entirely by third parties - and that profitability in the industry could thus come 
eventually rely only on an automaker's ability to brand and to sell (and perhaps to finance those sales).

It is this tendency toward extremes that makes the evolution of this particular vertical company a particularly good place to glean insights into a topic long of great concern in organization studies: the need to understand variation across firms - in this case assemblers and their suppliers - regarding where to draw boundaries and how to manage interdependence. For as the trend towards outsourcing has matured and the industry has given up the ghost of total modularity, assemblers have ceased to obsess only with the reduction of fixed costs and the reduction of the vertical scope of the firm. Indeed, field studies today increasingly find that managers have become much more interested in what we might call vertical composition, by which we mean that firms today are often simultaneously in-sourcing activities previously outsourced even as they outsource other activities previously governed by hierarchy.

As MacDuffie (2008) and others have shown, despite considerable efforts by automakers to develop the fully "modular" automobile characterized by standard interfaces between components, the reality is that cars continue to manifest a "persistently integral" product architecture. ${ }^{24}$ Yet MacDuffie also makes clear that this has by no means settled the larger question that modularity was supposed to settle, viz. how to discern the governance implications of a particular product architecture. To the contrary, because these failures have been intriguingly varied and partial ${ }^{25}$ - most automakers today use a "mix of modular and nonmodular elements" - the industry today is made up of companies that must try to "develop the capability to experiment and move activities back and forth across organizational boundaries." All they can do, MacDuffie writes, is put themselves in a position to "choose to move towards greater product modularity where it increases positive outcomes and avoids negative outcomes and otherwise to embrace persistent product integrality" and the complex relationships with suppliers that it is understood by all to entail.

MacDuffie (2008) is surely right that experimentation drives the co-evolution of organizational structure and product architecture. But if we want to draw upon that observation to say anything substantive about the dynamics of today's vertical production networks, we need also to know how firms in the contemporary decentralized production regime decide what constitute positive and negative outcomes. These, of course, are (definitionally) measured against the goals of the firm - which is what brings the study of inter-organizational dynamics back to March's conception of the firm as a political coalition and especially to his recognition that "the composition of the firm is not given; it is negotiated" and that "the goals of the firm are not given; rather, they are bargained." Or at least it brings us back to March so long as we also recognize that transactions between assemblers and suppliers are much more complicated than they were in 1962 and that this has altered coalitional politics.

\footnotetext{
${ }^{24}$ See especially Herrigel (2004) and Sabel and Zeitlin (2004).

${ }^{25}$ MacDuffie (2008) writes that is "possible - even likely - that product architecture could be described as modular in some aspects (e.g. high modularity-for-production vis-à-vis large, high value-added assemblies at Hyundai) and as integral in other aspects (e.g. persistent interdependencies vis-à-vis certain performance characteristics." Yet even as automakers have learned that they can mix elements, they have still found it extremely difficult to infer just what mix best fits a particular production network, as the answer cannot readily be inferred from that network's organizational and relational structure.
} 
And this brings us back to our case. In our recounting of the evolution of the production network that revolves about Fiat Auto, we have sought to trace coalitional politics as they have been negotiated not only within the automaker but also between the automaker and the many and varied suppliers upon which it has come so heavily to rely, and we have paid particular attention to the rise and fall of company's attachments to strategies premised on architectural and artefactual means of easing the coordination of relationships across firm boundaries. We have done so because - in our (and Barley and Kunda's) terms - that rise and fall has been so fundamentally marked by ideological conflicts over just what a radical outsourcing strategy entailed, due not least to the ways in which relational legacies have shaped patterns of alliance and thus driven differences in the "stream[s] of discourse that promulgate[d], however unwittingly, [sets] of assumptions about the nature of the objects with which [they] dealt" (Barley and Kunda 1992).

Specifically, we have argued in our first moment that an overarching consensus across the production network that some restructuring of the division of labor between Fiat and its suppliers was necessary was splintered by rivalries internal to Fiat. On one side was a technical division wary of the capabilities of the company's historic Italian supply base, enamored of the possibility of acceding to cutting edge technology with a minimum of investment, and thus committed to the establishment of alliances with global systems suppliers in the long-term development of relatively generic engineering solutions to be applied across models. On the other, however, was a faction that similarly saw great possibilities in a modular outsourcing strategy, but that was more fearful of holdup risks. Under the (ideological) assumption that a modular product architecture would ensure some relative standardization of components, this faction sought to prevent "associations" between systems and module suppliers. They did so by directing some component supply to allies among historic Fiat suppliers. These allies that were perhaps relatively limited in terms of R\&D capabilities, but were willing to bend over backwards to contain costs and to accept the company's often chaotic new product development procedures. This "eugenic" strategy, however, ultimately undermined many of the efforts of the first group and made suppliers less wary to commit to Fiat's modular strategy.

In our second moment, we traced the key implications of these differing understandings of the possibilities and constraints contained in Fiat's approach to modularity and outsourcing. We argued that the presumption that component standardization would follow in a relatively straightforward manner from a modular product architecture led to a reorganization of new product development procedures that isolated product development platforms under the control of "heavyweight" product managers. Given that Fiat had not in fact developed a sufficiently modular product architecture to obviate significant and complex coordination in the process of system integration, and given considerable pressures to get product out the door, these managers dealt with their ensuing difficulties by forming a series of only weakly overlapping alliances with suppliers in a process of network balkanization that made component standardization all but impossible.

In our third moment, we argued that the crisis that struck the company in 2002 led to a change of regime, in the sense that it undermined proponents of a particular understanding of modularity as a means to managing the radical outsourcing of production and design. However, while the crisis was catalytic of change, it was not determinative of that change, in the sense that the directions 
taken in the company's ensuing efforts to recover must be read in light not only of the resource constraints imposed by the previous regime's active-hollowing out of competencies in component design, but also in light of the way that hollowing out has shaped the understandings that both Fiat personnel and suppliers have developed regarding the relationship between product architecture and relational strategies.

In describing these moments, we have sought to show that the evolution of the production network in question can only be understood if we explicitly recognize that the strategy of the central actor - Fiat Auto - both affects, and was affected by, coalitions that include actors external to the organization. Indeed, Fiat's slow reaction to its problems was a consequence of the fact that the dominant coalition was able to co-opt local suppliers and was able point towards reduced costs to ensure its legitimacy. If the company's current dominant ideology is in fact a winning one, its continued recovery would seem to depend not only on suppliers willingness to commit resources to the design of models that are "derivative" of the "templates" that Fiat has sought to use to rebuild internal competencies, but also of the company's own ability to maintain an internal coalition commited to the reacquisition of those competencies. Whether this will occur, of course, will be bargained among many potential constituents. For this vertical network firm is a political coalition, guided by an executive at Fiat that must be a political broker, beholden to many parties as he negotiates not simply the composition of Fiat, but the composition of a much broader network linked in many cases not by ownership, but rather by a combination of contract and familiarity. 


\section{References}

Azoulay, Pierre (2003) 'Agents of Embeddedness', NBER Working paper 10142.

Baldwin, Corliss and Clark, Kim (2000) Design Rules: Volume 1. The Power of Modularity, Cambridge: MIT Press.

Barley, Stephen R. and Kunda, Gideon (1992) 'Design and Devotion: Surges of Rational and Normative Ideologies of Control in Managerial Discourse', Administrative Science Quarterly 37(3): 363-399.

Baum, Joel and Ingram, Paul (2002) 'Interorganizational learning and network organizations: Toward a behavioral theory of the "interfirm", in M. Augier and J. March (eds) The Economics of Choice, Change, and Organization. Essays in the memory of Richard M. Cyert, Cheltenham UK: Edward Elgar.

Camuffo, Arnaldo and Volpato, Giuseppe (2002) 'Partnering in the global auto industry: the FIAT-GM strategic alliance', International Journal of Automotive Technology and Management 2(3): 335-354.

Carruthers, Bruce and Uzzi, Brian (2000) 'Economic Sociology in the New Millennium', Contemporary Sociology 29(3): 486-494.

DiMaggio, Paul (2001) 'The Futures of Business Organization and Paradoxes of Change', in P. DiMaggio (ed) The twenty-first-century firm: changing economic organization in international perspective, Princeton: Princeton University Press.

Enrietti, Aldo (1995) 'Il settore dei componenti auto: struttura e dinamica', Economia e politica industriale 88: 131-151.

Fixson, Sebastian, Ro, Young and Liker, Jeffrey (2005) 'Modularisation and outsourcing: who drives whom? A study of generational sequences in the US automotive cockpit industry', International Journal of Automotive Technology \& Management 5(2): 166-183.

Gantman, Ernesto (2005) Capitalism, Social Privilege and Managerial Ideologies, Ashgate:

Aldershot.

Helper, Susan, MacDuffie, John Paul and Sabel, Charles (2000) 'Pragmatic Collaborations: Advancing Knowledge While Controlling Opportunism', Industrial and Corporate Change 9(3): 443-483.

Herrigel, Gary (2004) 'Emerging Strategies and Forms of Governance in the Components Industry in High Wage Regions', Industry and Innovation 11(1/2): 45-80.

Herrigel, Gary and Wittke, Volker (2004) 'Varieties of Vertical Disintegration: the Global Trend Toward Heterogenous Supply Relations and the Reproduction of Difference in US and German Manufacturing', in R. Whitley, G. Morgan and Moen (eds) National Business Systems in the New Global Context, Oxford University Press: Oxford.

Jones, Candace, Hesterly, William and Borgatti, Stephen (1997) 'A general theory of network governance: Exchange conditions and social mechanisms', Academy of Management Review 22(4): 911-945.

Kristensen, Peer Hull and Zeitlin, Jonathan (2004) Local Players in Global Games: The Strategic Constitution of a Multinational Corporation, Oxford: Oxford University Press (forthcoming).

MacDuffie, John Paul 2008 'Technological and Organizational Barriers to Modularity:Persistent Integrality in the Global Automotive Industry' Mimeo, Philadelphia: Wharton. 
March, James (1962) 'The Business Firm as a Political Coalition', Journal of Politics 24: 662678.

Michelsons, Angelo (2001) 'Grande fabbrica e minime imprese: l'indotto Fiat negli anni del 'boom economico", in F. Amatori and A. Colli (eds) Comunita' di imprese: Sistemi locali tra ottocento e novecento, Bologna: Il Mulino.

Pettigrew, Andrew (1977) 'Strategy formulation as a political process', International Studies of. Management and Organization 7(2): 78-87.

Podolny, Joel and Page, Karen (1998) 'Network Forms of Organization', Annual Review of Sociology 24: 57-76.

Powell, Walter (1990) 'Neither Market Nor Hierarchy: Network Forms of Organization', in B. Staw and L. L. Cummings (eds) Research in Organizational Behavior, Vol. 12, Greenwich, CT: JAI Press.

Sabel, Charles and Zeitlin, Jonathan (2004) 'Neither Modularity nor Relational Contracting: Inter-Firm Collaboration in the New Economy ', Enterprise and Society 5(3): 388-403. Sanchez, Ron and Mahoney, Joseph (1996) 'Modularity, Flexibility, and Knowledge Management in Product and Organization Design', Strategic Management Journal 17: 63-76.

Smith-Doerr, Laurel and Powell, Walter (2005) 'Networks and Economic Life', in N. Smelser and R. Swedberg (eds) The Handbook of Economic Sociology, Second Edition, Princeton, NJ: Princeton University Press.

Sturgeon, Timothy (2002) 'Modular Production Networks: A New American Model of Industrial Organization', Industrial and Corporate Change 11(3): 451-496.

Takeishi, Akira and Fujimoto, Takahiro (2001) 'Modularisation in the auto industry: interlinked multiple hierarchies of product, production and supplier systems', International Journal of Automotive Technology \& Management 1(4): 379-396.

Veloso, Francisco 2000 'The automotive supply chain organization: Global Trends and Perspectives', Cambridge MA: Massachusetts Institute of Technology.

Whitford, Josh and Enrietti, Aldo (2005) 'Surviving the fall of a king: The regional institutional implications of crisis at Fiat Auto', International Journal of Urban and Regional Research 29(4).

Zirpoli, Francesco and Becker, Markus 2008 'Organizing Complex Product Development: Outsourcing, Performance Integration and the Role of Product Architecture': Available at SSRN: http://ssrn.com/abstract=1087236.

Zirpoli, Francesco and Caputo, Mauro (2003) 'The Nature of Buyer-Supplier Relationships in Co-Design Activities: The Italian Auto Industry Case.' International Journal of Operations and Production Management. 